Wegeirn, H.: Das Holz als Rohstoff. 2. Aufl. München 1955. - Weitland, J.: Jahrringchronologische Untersuchungen an Laubbaumarten Norddeutschlands. Diss. Hamburg 1960. WIII IAms, S.: Secondary vascular tissues of the oaks indigeneous to the U. S. I-IIII. Bull. Torrey Bot. Club. 66, 353-365 (1939), und 69, 1-10 und 115-129 (1942).

\title{
II. MITTEILUNGEN
}

\section{FAO/IUFRO Symposium on Internationally Dangerous Forest Diseases and Insects}

Vom 20. bis 30. Juli 1964 hat die FAO eine Sondertagung der IUFRO im Commonwealth Forestry Institute, Oxford, einberufen. Gegenstand der Tagung ist die Behandlung international schädlicher Forstkrankheiten und Forstinsekten. Alle Forstministerien und die der Union der Forstlichen Forschungsanstalten angehörenden Institute werden direkt Einladungen erhalten. Wissenschaftler, die beabsichtigen, daran teilzunehmen, „sollen mit ihren Regierungsstellen Kontakt aufnehmen und sich in die Delegation ihres Landes einschreiben lassen“. Die Teilnahme steht jedem offen, doch ist mit Reisekostenzuschüssen seitens der FAO nicht zu rechnen. Die Forstpathologen und die Forstentomologen werden teils gemeinsam, teils getrennt tagen.

\section{BUCHBESPRECHUNGEN}

Steuerforstwirt. Steuernachschlagewerk für die Land- und Forstwirtschaft. Von Forstingenieur Hermann Tischendorf unter Mitarbeit von Dr. H. Fuhrmann, abs. jur. H. Grundschober, Dr. M. Kampler, Dipl.-Ing. W. Kieslinger, Dr. K. Martellanz, Dipl.-Ing. W. Purrer, Fin.-Sekretär O. STEJSKal. Loseblatt-Kommentar in Halbleinen, Ordner mit Ringmechanik und Griffindex. Grundwerk 600 S. Großoktav (DIN A 5), Graz-Salzburg 1963. Für das Bundesgebiet zu beziehen bei: Verlag „Steuerforstwirt", 8228 Freilassing/Obb., Postfach 519. 56,-DM.

Das vorliegende, ganz auf die Bedürfnisse der Praxis zugeschnittene Werk kann mit Recht den Anspruch erheben, als Steuernachschlagewerk für die Land- und Forstwirtschaft bezeichnet $\mathrm{zu}$ werden. Es werden darin die für die Land- und Forstwirtschaft bedeutsamen Rechtsvorschriften auf dem Gebiet der Einkommensbesteuerung, der Umsatzbesteuerung, der Vermögensbesteuerung, der Erbschafts- und Schenkungsbesteuerung sowie der Grunderwerbsbesteuerung behandelt. Den besonderen Bestimmungen über die Pauschalierung wurde ein eigener ausführlicher Abschnitt gewidmet. Desgleichen wurden in jeweils eigenen Abschnitten die Bewertungsvorschriften, die Vorschriften über die Stempel- und Rechtsgebühren, ferner das Verfahrensrecht und die Buchführungsvorschriften behandelt. Nach dem Vorwort des Herausgebers konnten für die Bearbeitung der bis jetzt noch nicht erfaßten Gesetze (Beförderungssteuer, Bodenwertabgabegesetz, Erbschaftssteueräquivalentgesetz, Grundsteuergesetz u. a. m.) bereits einc Reihe von Experten gewonnen werden. Im Zuge der periodischen Ergänzungen sollen auch noch diese Gesetze und darüber hinaus noch eigene Abschnitte über land- und forstwirtschaftliche Kennzahlen (Maße, Gewichte, Preise, Erfahrungszahlen, Faustregeln, Ernteergebnisse), über land- und forstwirtschaftliche Rechtsbegriffe (Fruchtgenuß, Ubergabe-, Pacht-, Kauf-, Angestellten-, Werkvertrag usw.) sowie über land- und forstwirtschaftliche Lohnsteuer einschließlich Kinderbeihilfefonds gebracht werden. 